\title{
Health promotion and work: prevention of shift work disorders in companies
}

\author{
Kneginja D. Richter • Jens Acker • Friederike Scholz • \\ Günter Niklewski
}

Received: 1 October 2010 /Accepted: 11 November 2010 /Published online: 8 December 2010

(C) European Association for Predictive, Preventive and Personalised Medicine 2010

\begin{abstract}
Workplace health promotion is a strategy to improve the health and well-being of people at work. The measures aim at the personal, organisational and work environment. Shift work is one of many reasons provoking increased job stress. According to worldwide epidemiological data, up to $30 \%$ of the working population are employed in shifts. Taking into consideration that shift work causes a large number of somatic and psychiatric diseases which bear considerable negative consequences for the health status and the quality of life, it seems to be important to initiate health promotion strategies for shift workers in the companies. The results of recent studies indicate that well-scheduled und targeted health programmes can change the lifestyle of shift working employees and have an impact on the risk factors involved. One problem, though, is a considerable time lag till effects become apparent; therefore, the long-term economic effects of workplace health promotion have not been evaluated sufficiently to date. These definitely positive effects highlight the demand for trainings and workshops for people in shift work. We urgently suggest a speedy implementation of the recommended strategies by companies with shift work systems. In our view, this poses a challenge to the "infant" interdisciplinary field of sleep medicine that should be solved.
\end{abstract}

Keywords Health promotion $\cdot$ Health Prevention $\cdot$ Shift work $\cdot$ Shiftwork sleep disorder $\cdot$ Companies

kneginja richter and jens acker should have equaly autorship.

K. D. Richter $(\bowtie) \cdot J$. Acker $\cdot$ F. Scholz $\cdot$ G. Niklewski

Clinic for Psychiatry and Psychotherapy,

Prof. Ernst-Nathan Str.1,

90419, Nuernberg, Germany

e-mail: Kneginja.Richter@gmx.de

\section{Introduction}

Health promotion and prevention in companies will become more important in the 21 st century because a reduction of the individual and social health costs by special interventions is expected [24].

Nevertheless, the further popularisation of innovative concepts of health promotion in companies is still in great need of improvement. Recent surveys suggest that the diffusion of health prevention measures in Germany does not reach the minimum standard, because only $20 \%$ of all interviewed enterprises take action in line with health promotion [35].

The negative impact of shift work on the health of workers is high, but established strategies for health promotion for shift workers and the prevention of shift work sleep disorders have not been implemented yet [22].

In the current literature, the terms "health promotion" and "prevention" are often used interchangeably. In spite of different conceptual approaches, these strategies target the overarching objective of improving the health of individuals.

\section{Prevention}

From a historical point of view, disease prevention is the older concept; it arose from the social medicine of the 19th century and focussed on interventions to prevent the development of diseases or rather to avoid the spread of infectious diseases.

A prerequisite is, however, that pathogenetic coherences such as developmental stages and the progress of diseases are already known [30].

The prevention of the shift work sleep disorder and the prevention of the somatic diseases caused by shift work 
mean that preventive measures should centre on shift workers who already have early symptoms of the disease [36].

\section{Health promotion}

The term "health promotion" has its origins in the debates of the World Health Organisation (WHO) about health-care policy including political and cultural as well as economic and social aspects.

Health promotion is used to strengthen individual life skills. The interventions of health promotion target the improvement of economic, cultural, educational and hygienic living conditions of the population. Health promotion pursues a promotion strategy to strengthen personal responsibility [27].

Five action areas for health promotion were identified by the Ottawa Charter [41, 44] in 1986: 1) establishing a public policy on health 2) creating supportive environments, 3) strengthening community action, 4) developing personal skills and 5) re-orientating health care services toward the prevention of illnesses and the promotion of health.

Therefore, the WHO highlights the independence of promoting health and discriminates health promotion from usual prevention measures [5].

\section{Workplace health promotion}

Workplace health promotion is a strategy to improve the health and well-being of people at work. The measures aim at the personal, organisational and work environment.

In Europe, the foundation of workplace health promotion was laid in 1997 by the Luxembourg Declaration on Workplace Health Promotion in the European Union. The declaration was updated last in 2007 and signed by more than 100 companies [37].

Organisations of all 27 member states participate in the European Network for Workplace Health Promotion (ENWHP). All of the network members aim to improve workplace health and well-being in the companies. Identifying and disseminating good workplace health promotion practice and creating supporting national infrastructures in the form of national networks to share experience and knowledge at the European level are targets the ENWHP is trying to achieve in the future [34].

In the field of mental disorders, workplace prevention measures are well known; here, the majority of strategies operate on the individual level.

Most work health promotion programmes focus on the following topics: promotion of physical activity, coping with stress and nutritional improvement. The health promotion courses can trigger improvements of high effect sizes with regard to health behavioural patterns and of moderate effect sizes with regard to physical complaints, subjective health ratings and health-related quality of life [29].

Health promotion strategies for shift workers should be implemented in the future.

Job stress and shift work

The US National Institute for Occupational Safety and Health defines job stress as "the harmful physical and emotional responses that occur when the requirements of a job do not match the capabilities, resources, or needs of the worker" [38].

Job stress can be triggered by work itself (heavy workload, low input on decision making) or by the organisational context of work.

There are wide interindividual limits of variation with regard to the felt stress with interaction between personal (e.g. coping strategies) and situational (e.g. support by superiors) parameters [40].

It is renowned that shift work increases the subjective strains of work. Elevated consume of sleep medication, high frequency of difficulties to fall or stay asleep and higher rates of substance abuse were specified [23].

Increased importance is attached to the organisation of working time, which can be derived from the inclusion of this topic in the reports by the German federation of trade unions about the creation of a job satisfaction index. The index is to provide public information on the prevailing working conditions in Germany. It includes data about the opportunity to have working schedules organised by the individual as well as to take into account personal needs in the organisation of working time [22].

In $2009,28 \%$ of the people employed worked in night shift (between 10 p.m. and 5 a.m.). [15] At the same time, more than $40 \%$ of the employees asked reported that they did not have any possibility to impinge on the organisation of their working schedule.

In the"Good work"concept, working time is one part of the overall index developed to promote the improvement of work reality and to support professional and occupational political initiatives. Over the course of time, the improvement of operational working conditions shall be achieved [15].

Shift work is widespread in modern industrialised societies and requires the social adjustment of the individual to the modified surrounding conditions both at work and in private life. Consequently, working in shift systems comes across as a model stressor in the field of sleep medicine $[2,23]$.

Shift work is one of many reasons provoking increased stress at the job. Shift work produces similar effects on 
human beings as stress, especially with people who are not able to dissociate themselves from work place troubles in their leisure time [1, 44].

Stress has negative effects on the autonomic nervous system, causes an imbalance of the sympathetic and parasympathetic nervous system and leads to an accumulation of stress- related cardiovascular diseases [54].

Taking into consideration that shift work causes a large number of somatic and psychiatric diseases which bear enormous negative consequences for the health status of employees and worsen their quality of life, it seems to be important to initiate health promotion strategies for shift workers in the companies [39].

Besides the consequences on the health status, the highest damage produced by shift work disorder is assumed to be due to the increased suffering from fatigue and accidents caused by tired shift workers [44].

Although the shift work disorder has severe economic consequences for society as a whole and health-related consequences for the individual, solid recommendations for health promotion and the prevention of these disorders do not exist yet.

\section{Shift work disorder}

Shift work disorder is a clinically recognised condition that develops in some individuals who work at night, start work early in the morning (4 a.m. to 7 a.m.), or work according to a rotating-shift schedule. Shift work disorder includes more severe symptoms than sleep disturbances [12, 14].

Shift work sleep disorder consists of symptoms such as insomnia or excessive sleepiness that occur as transient phenomena in relation to work schedules. (The International Classification of Sleep Disorder, Diagnostic and Coding Manual. American Academy of sleep medicine 2001). The occurrence of the shift work disorder in shift workers increases in relation to the growing amount of people working in shift systems.

In 1904, 2,8\% of all employees in Western Europe worked in night shift; nowadays, a quarter of the overall amount of the employed persons in Europe and the United States of America operate in shift work [7].

$24 \%$ of all employed persons in Europe work in the regular work schedule from 7 a.m. to 5 p.m., thus working at atypical labour times and shift work are rampant [10].

In 2003, the percentage of shift workers in relation to the total number of employed persons in Europe was about $15.5 \%$.

The increase in shift work became particularly apparent in Portugal and Greece, where the proportion of shift work respectively almost tripled within 10 years.

It is immediately obvious that the percentage of shift workers in some eastern EU states is very high: with $36.9 \%$ in Poland, 31.7\% in Slovenia, 29.4\% in the Czech Republic and $26.3 \%$ in Slovakia, these countries show proportions in shift work that exceed the averages of the other EU states considerably. One reason for this phenomenon may be found in the stronger dominance of industrial production in these states [26, 32].

Concerning the incidence of sleep disorders caused by shift work in Germany, reliable data is not available. According to international studies, $29 \%$ to $38 \%$ of employed shift workers record grievances of insomnia as compared to $5 \%$ to $29 \%$ in the non-shift-worker-sample [10].

Further epidemiological analysis revealed that $32 \%$ of the night working employees and $26 \%$ of the employees working in three rotative shifts experience insomnia or excessive sleepiness in comparison with $18 \%$ of employees who work daytime exclusively [16].

$8 \%$ of the people working in three shifts and $5 \%$ of the night shift workers show symptoms of the circadian sleep/ wake rhythm disorder of the shift work syndrome [19].

According to further studies, $2 \%$ to $5 \%$ of the shift workers suffer from shift work syndrome [3].

Predominant symptoms of the shift work syndrome are sleepiness, the inability to fall or stay asleep, false awakening, reduction in performance, lapse in concentration and fatigue. Therefore, complaints of insomnia as well as difficulties to fall asleep and the inability to stay asleep are an inherent part of the shift work sleep disorder $[42,3]$.

\section{Sleep disorders in shift workers}

Night employment leads to a shortening of sleep time and a reduction of sleep quality.

Employees in shift work complain about short sleep time after work and insufficiently deep sleep state. Typical sleep time is about $3 \mathrm{~h}$ to $4 \mathrm{~h}$ wherefore sleep is experienced as not refreshing and people feel tired after waking up [10].

An early start of work at about 4 a.m. to 7 a.m. can be accompanied by difficulties to fall asleep as well as incidents after awakening. These kinds of sleep/wake rhythm disorders result in increased daytime sleepiness and consequently in a lack of concentration, tiredness at the workplace, insufficient relaxing, fatigue and an increasing error ratio at the work place $[42,3]$.

The accumulation of sleep deprivation leads to further complaints such as muscular and spinal column pain, overstrained eyes, vertigo, fatigue and increased excitability. In consequence of these discomforts, the sleep deprivation results in a higher vulnerability to stress impacts [1].

According to Fröberg, an explanation of the increased sleepiness in shift workers is that the employee has to work at times when the body should have the lowest level of 
metabolism. Furthermore, the author suggests that the sleep time in the daytime is shorter after night shifts and that therefore short attacks of sleep occur in the night. The sleep deficit will be compensated by daytime sleep in the afternoon [21]; its duration of more than $1 \mathrm{~h}$ mostly proportionally increases to the reduction of sleep time in the night before [13]. Vigilance and alertness as well as the metabolism of the human body reach their peak in the afternoon, the highest point of work efficiency is in the morning hours. But for shift workers, after night shift the morning is reserved for sleeping.

In a recent survey of 3000 German employees conducted by the DAK insurance company (2009), 46.9\% of those asked stated to be affected by mild, moderate or severe sleep disorders. $34.1 \%$ of the people suffering from a severe sleep disorder were employed in shift work (Fig. 1).

1407 DAK insurants with sleep disorders were asked about the origin of their disturbed sleep. $41.5 \%$ of the interviewees cited shift work or modified sleep-wake rhythm (normal sleep rhythm: 11 p.m. to 7 a.m.) as possible reasons following behind stress and extraordinary strains.

These study results clarify that sleep disorders are one of the most frequent impairments to health and that they are highly prevalent.

In the subsample of shift workers, about $16 \%$ "often" or "very often" feel the urge to fall asleep at their place of employment. Of those employees suffering from severe sleep disturbances, $31 \%$ reported that they tended to fall asleep during working hours (Fig. 2) [33].

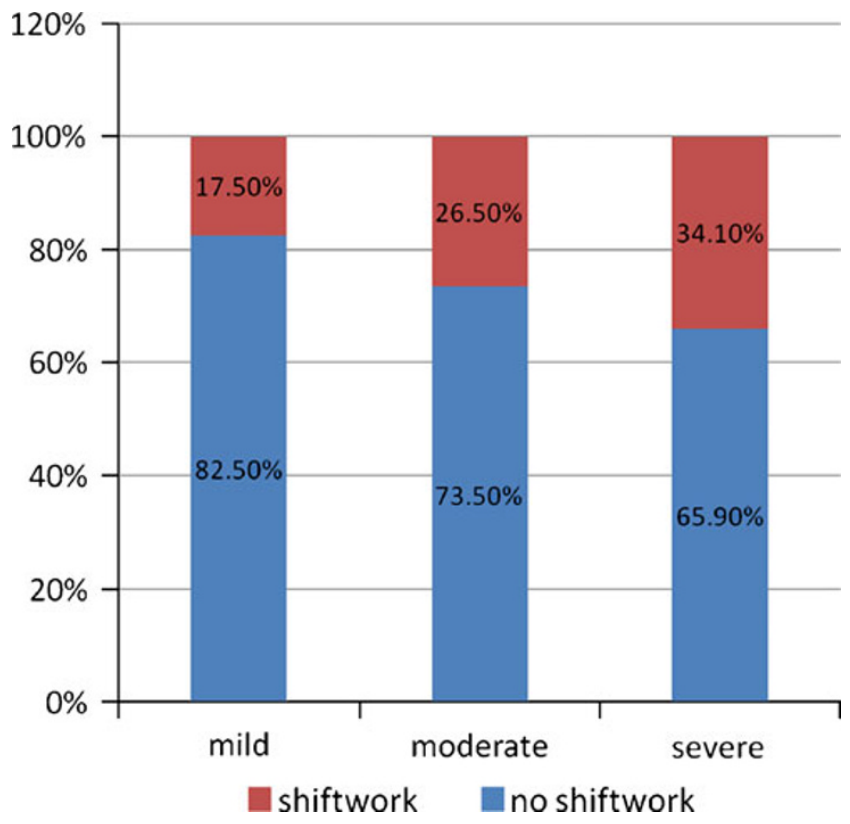

Fig. 1 Sleep problems related to shiftwork. DAK Gesundheitsreport 2010. IGES Institut Gmbh, Februar 2010

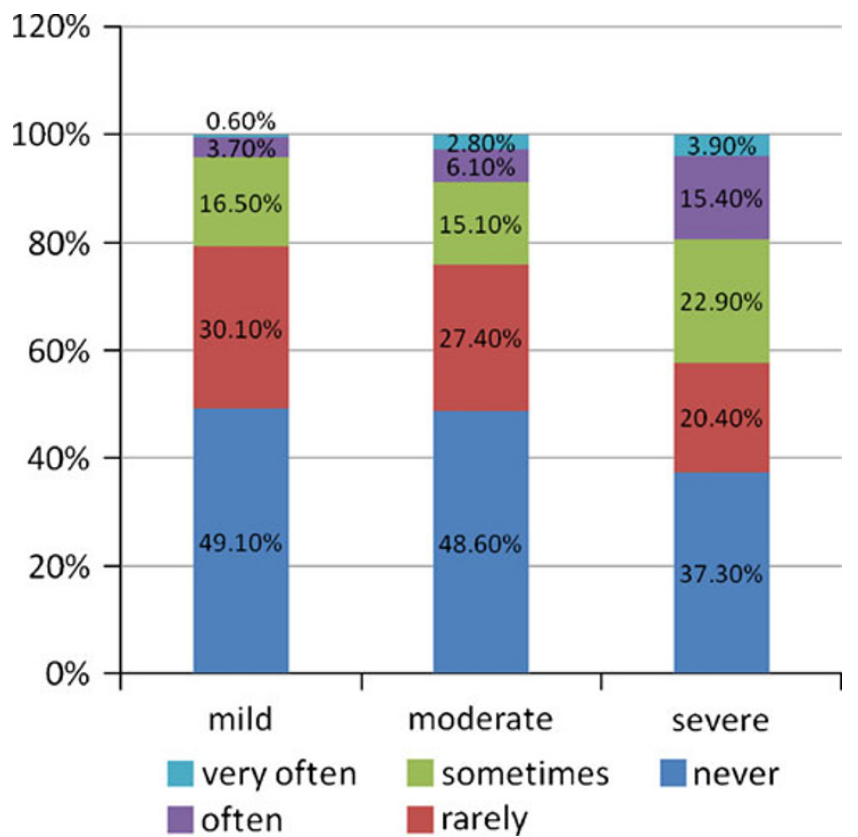

Fig. 2 Frequency of urge to fall asleep by severity of sleep disorders $(n=1.407)$

Numerous studies prove the correlation between quality of sleep and human functionality. Notwithstanding the evidence of the correlation between quality of sleep and human functionality in the daytime, there is a lack of inhouse counselling lessons informing about strategies to improve the quality of sleep.

Health aspects of sleep disorders in shift workers

\section{Physical implications of shift work}

Shift work highly correlates with several physical impairments such as cardiovascular and gastrointestinal diseases, breast cancer, metabolic syndrome, diabetes mellitus, sleep disorders and fatigue.

Sleep disorders and elevated tiredness [44] are most frequent in shift working employees and the main reasons to resign from shift work. The following impairments also coexist with shift work: hearing impairment, dermatosis, headache, back pain, injuries, stress and increased irritability.

Approximately $68.3 \%$ of the shift working staff in night work consider shift work to influence health in a negative way, $57.4 \%$ of the daytime workers agree with this opinion [46].

Working on Sundays was specified to have negative effects on health by $66.9 \%$ of employees working on Sundays in contrast to $57 \%$ who do not work on Sundays. $67.6 \%$ of the employed people associate tiredness, insomnia and stress with frequent alternations in work schedules $[45,39]$. 
Women working in shift work have a higher risk of developing breast cancer as compared to women working in daytime shifts $[18,25]$.

Gastric ulcer is one of the most common gastrointestinal diseases that occur in shift workers. This may arise from employees eating less or too much during night shifts, which affects the stomach because of the deceleration of gastrointestinal functioning at night. The risk of unhealthy eating habits arises from the absence of opportunities to prepare substantial meals. A higher caffeine intake is associated with shift workers to increase their alertness following a frequent incidence of gastric ulcer.

Numerous surveys proved a higher occurrence of cardiovascular diseases such as coronary heart disease, myocardial infarction and angina pectoris in shift working people as compared to day shift workers. So far, the mechanism mode behind this finding has not been adequately explained. Dietary changes, disturbed appetite and sleep disorders are part of an explanation of the cardiovascular disturbances initiated by shift work.

Increased smoking habits and raised blood pressure are other reactions triggered by the high stress level occuring at night work [6].

Diabetes mellitus and metabolic syndrome are more common in shift workers. Furthermore, studies reveal that the serum concentration of potassium, urea, glucose, cholesterol and blood lipids is elevated in shift working employees in comparison with non-shift-working colleagues. [52] Recent studies have shown a possible negative influence of sleep deprivation on the blood glucose level. Niedhammer et al. compared the bodymass-index of 469 nurses working night shifts with daytime nurses over a period of 5 years, finding a higher BMI in nurses of the night shift. [41] According to Koller et al., there is a higher prevalence of diabetes mellitus with employees in shift work [32].

Some epidemiological researches show higher blood triglyceride levels in shift workers. One study from Buffalo/ NY produced the following results: based on a sample of 98 police officers, the study showed that the night shift working employees more frequently developed metabolic syndrome than the police officers working in day shift [53].

Influence of shift work on mental health

A disturbed sleep-wake-cycle influences the state of mental health in a negative way. Therefore, anxiety disorders and depressive symptoms are common in shift working people as well as decreased concentrativeness and ability to respond and a lack of motivation and memory [9].

For mental health reasons, it is important to emphasise the necessity of special programmes for advanced training (and education) to prevent mental illness in shift workers.
According to a study by Takahashi, the development of depressive symptoms in shift workers is more likely with industrial unrest [31 55].

The risk of alcohol abuse in shift working employees is elevated as well because of the sedative effect of alcoholic beverages.

\section{Examples of programmes for health promotion and prevention of shift work disorders in companies}

A multitude of publications making recommendations on the prevention of shift work syndrome and health promotion for shift workers exist $[4,11,48,49]$; in contrast, the number of evaluations of those programmes is very low.

Measures of workplace health promotion could be more successful by complying with the following requirements:

- Elaborated planning and purpose

- Long-term strategy

- Verification with maintenance of the purposes

- Ongoing individual servicing and counselling

- Adequate intensity and continuity

- Large number of participants

- Integration of measures in the company philosophy and culture

- Promotion by the surrounding field

- Mutual assistance by trainings in groups

The results of recent studies indicate that well-scheduled und targeted health programmes can change the lifestyle of shift working employees and the risk factors involved, this happens, however, with a considerable time lag; therefore, the long-term economic effects of workplace health promotion have not been sufficiently evaluated to date.

In contrast, the short-term consequences of absenteeism rate and productivity have been examined more thoroughly [43].

Example of shift work counselling by the company circadian

Circadian is an international consultancy that has been advising shift workers for 20 years and supports them to cope with the consequences and challenges of shift work. Its main aim was the reduction of costs for the company and the maximisation of profits. The Circadian measure is led by an expert coach and focuses on manager counselling on appropriate types of shift systems from the point of view of the employees and the company, on the identification of early health impairments of employees and on learning behavioural rules of conduct for a better handling of shift work. The Circadian consultancy gives advice to the dependants to establish a better understanding of the modified rhythm of life and to build up acceptance of the 
shift worker's needs. The four-hour workshop provides practical information and suggestions for the improvement of health, including advice on healthy, balanced nutrition, strategies to deal with sleepiness, ways to increase alertness, methods to improve the quality of sleep, the recommendation of an afternoon nap and advice on worklife-balance. Workshops on the job are more effective than optional workshop attendance off-time. Prior to the workshop, details on sleeping habits were determined and collected over a period of 28 days. Six weeks after the final seminar, the questionnaires were analysed and compared with the results of the first survey. The statistical evaluation revealed significant differences in the following aspects: $41 \%$ of the workshop participants believe to be able to manage routine activities at home better after the workshop as compared to $23 \%$ of the participants before the workshop.

Afterwards, $77 \%$ of the participants reported an improvement of their general state of health as compared to $59 \%$ previously. Especially the gastrointestinal complaints improved significantly, caffeine intake was reduced, sleep time was extended to $5.8 \mathrm{~h}$ from $4.8 \mathrm{~h}$ at the beginning of the workshop. About half of the participating employees carried out changes in their sleeping environment. The sleep improvement correlated with increased alertness and safety at the work place.

These definitely positive effects accentuate the demand for trainings and workshops for shift working people [28].

Address:

Corporate Headquarters

CIRCADIAN ${ }^{\circledR}$

2 Main Street, Suite 310

Stoneham, MA 02180

USA
Fatigue programme of the Washington state nurses association

The following guidelines for the prevention of and coping with fatigue in shift working nurses were drawn up as a "white paper":

Provide education for all care providers on the hazards and causes of fatigue, recognising fatigue and the obligation of individuals to assure that they are able to provide safe care.

Establish guidelines and training for workers on the use of multiple fatigue countermeasures including controlled rest periods.

Provide education for all shift workers regarding the hazards of shift work and the measures that can be taken to mitigate these hazards and promote healthy wake and sleep patterns.

Institute policies regarding shift work that will promote health and enhance work-life-balance for workers [17].

Managing shift work in European air traffic companies

This study illustrates the results of a survey among air traffic staff and the measures implemented by air traffic companies. Air traffic companies from Great BritainUnited Kingdom, USA, Canada, Australia, France, Germany, Denmark and Austria were involved.

The British airline companies established guidelines on shift rotation and the duration of working time [20].

In France, the effect of napping in pilots was examined and strongly recommended [8].

Austrian air traffic controllers were surveyed for improvement measures regarding the handling of shift work. Those interviewed asked for an education programme.

Table 1 Strategies for the improvement of shift work sleep disorder

\begin{tabular}{lll}
\hline Intervention strategies & Workplace & Individual level \\
\hline Organisational level & Intensity of illumination [50] & Educational events on: \\
\hline $\begin{array}{l}\text { Integration of measures in the company } \\
\text { philosophy and culture } \\
\text { Shift rotation }\end{array}$ & $\begin{array}{c}\text { Number of employees working in } \\
\text { night shift } \\
\text { Pressure to perform (task work } \\
\text { conditions) } \\
\text { Rest-Rooms } \\
\text { Warm Meals }\end{array}$ & $\begin{array}{l}\text { Sleep hygiene } \\
\text { Behavioural strategies to avoid fatigue }\end{array}$ \\
$\begin{array}{l}\text { Rest periods } \\
\text { Regular educational events for employers } \\
\text { Evaluation }\end{array}$ & $\begin{array}{c}\text { Napping } \\
\text { Information for relatives } \\
\text { Prevention of somatic and psychiatric symptoms } \\
\text { associated with shift work }\end{array}$ \\
\hline
\end{tabular}


In 2001, a comprehensive education programme for air traffic controllers was implemented in Canada. The following intentions contributed significantly to the success of the programme [38]:

1. Organisational commitment

2. Employer-employee partnership

3. Education and training

4. Employee health screening

5. Programme evaluation and refinement

\section{Conclusion and outlook}

Shift work affects the health and the productivity of the shift worker [47].

Therefore, the establishment of programmes for health promotion and the prevention of shift work disorder in companies is urgently required.

Although meaningful papers presenting recommendations for optimising the environments of shift work exist $[12,29,51]$, there is a need for scientific evaluation of the already implemented programmes in the companies which employ shift workers.

The well-known intervention strategies which operate on an organisational level by optimising the shift work system within the bounds of an enterprise through the management of the duration of shifts, shift rotation systems and rest periods should be completed by regular educational programmes.

Furthermore, the optimisation of workplace conditions e.g. the intensity of illumination and rest-rooms should follow.

It is well known that behaviour-preventive measures exceed the effects of measures of prevention adapting the working environment [22]. This means that educational programmes for shift workers should be a part of the health promotion measures because this education impacts on individual knowledge. The contents of the educational programmes, e.g. sleep hygiene, behavioural strategies to avoid fatigue, information for relatives, prevention of somatic and psychiatric symptoms associated with shift work, individual strategies to improve sleep quality and daily vigilance should prevent fatigue and sleep disorders and contribute strongly to the preservation of the physical health of shift workers (Table 1).

The realisation of these recommendations will only work if the regional networking between companies and health care institutions is intensified.

In order to reach the objective of empowerment on a local level, top-down measures (expert opinion, best available evidence) are to be combined with a bottom-up part taking into account regional characteristics and the special needs of the local workforce [36].
We urgently suggest the implementation of the recommended strategies by companies with shift work systems. In our view, this issues a challenge to the "infant" interdisciplinary field of sleep medicine that should definitely be solved.

\section{References}

1. Åkerstedt T, Torsvall L. Napping in shift work. Sleep. 1985;8:105-9.

2. Åkerstedt T, Kecklund G, Gillberg M, Lowden A, Axelsson J. Sleepiness and days of recovery. Transp Res. 2000;3:251-61.

3. Akertsedt T. Shift work and disturbed sleep/wakefulness. Occup Med (London). 2003;53(2):89-94.

4. Arnvig M, Beermann B, Köper B, Maziul M,Mellett U, Niesing C, Vogt J. Managing Shiftwork in European ATM. Literature Review. European Organisation for the safety of air navigation. 2006

5. Becker P. Prävention und Gesundheitsförderung. Gesundheitspsychologie. Ein Lehrbuch. 1997;Band 2:517-34.

6. Bøggild H, Knutsson A. Shift work, risk factors and cardiovascular disease. Scand J Work Environ Health. 1999;25:85-99.

7. Boivin DV, Duffy JF, Kronauer RE, et al. Sensivity of the human circadian pacemaker to moderately bright light. J Bio Rhythms. 1994;9(3-4):315-31.

8. Cabon P, Bourgeois-Bougrine S, Mollard R, Coblentz A, Speyer JJ. Flight and duty time limitations in civil aviation and their impact on crew fatigue: a comparative analysis of 26 national regulations. Hum Factors Aerosp Saf Int J. 2002;2(4):379-93.

9. Colligan MJ, Rosa RR. Shiftwork effects on social and family life. Occup Med. 1990;5:315-22.

10. Costa G. Shift work and occupational medicine: an overview. Occup Med (Lond). 2003;Band 53:83-8.

11. Costa G, Akerstedt T, Nachreiner F, Baltieri F, Carvalhais J, Folkard S, et al. Flexible working hours, health, and well-being in Europe: some considerations from a SALTSA project. Chronobiol Int. 2004; Band 21:831-44.

12. Culperer L. The social and economic burden of shift-work disorder. Suppl The J Fam Pract. 2010;59(1):S3-S11.

13. Czeisler CA, Johnson MP, Duffy JF, Brown EN, Ronda JM, Kronauer RE. Exposure to bright light and darkness to treat physiologic maladaptation to night work. $\mathrm{N}$ Engl J Med. 1990;322:1253-9.

14. Damien, Léger, Michel, Paillard Economics/Direct and Indirect Costs of Insomnia, Gallup study. 1991

15. DGB-Index Gute Arbeit GmbH (Hrsg): DGB-Index Gute Arbeit 2009. http://www.dgb-index-gute-arbeit.de/dgb-index_2009. [Stand: 13.09.2010].

16. Drake CL, Roehr T, Richardson G, et al. Shift work sleep disorder: prevalence and consequences beyond that of symptomatic day workers. Sleep. 2004;27:1453-62.

17. Ellis JR. Quality of care, nurses' work schedules, and fatigue: a white paper. Seattle: Washington State Nurses Association; 2008.

18. Erren TC, Falaturi P, Morferd P, Knauth P, Russel JR, Piekarski C. Schichtarbeit und Krebs. Deutsches Ärzteblatt. 2010;Ausgabe B:657-62.

19. Fell DL, Black B, et al. Driver fatigue in the city sleep patterns of shiftworkers. Accid Anal Prev. 1997;29(4):463-9.

20. Folkard S. Work hours of aircraft maintenance personnel, CAA Paper 2002/06. 1st ed. London: Civil Aviation Authority; 2003.

21. Fröberg JE, Karlsson CG, Levi L, Lidberg L. Psychobiological circadian rhythms during a 72-hour vigil. Försvarsmedicin. 1975; II:192-201. 
22. Fuchs T. Der DGB-Index Gute Arbeit. Fehlzeiten-Report 2009 2010: 175-195.

23. Gordon NP, Cleary PD, Parker CE, Czeisler CA. The prevalence and health impact of shiftwork. Am J Public Health. 1986;Band 76:1223-8.

24. Greef M de, Belgium NCO. Making the case for workplace health promotion. Analysis of the effects of WHP, 2004.

25. Hansen J. Light at Night, Shiftwork, and Breast Cancer Risk. JNCI J Natl Cancer Inst. 2001;93(20):1513-5.

26. http://www.destatis.de/jetspeed/portal/cms/Sites/destatis/Internet/ DE/Presse/pm/2004/12/PD04_545_133,templateId=renderPrint. psml (Stand 28.07.2010)

27. Hurrelmann K, Klotz T, Haisch J, Altgeld T. Lehrbuch Prävention und Gesundheitsförderung. Lehrbuch Gesundheitswissenschaften. Bern: Huber; 2010

28. Kerin, Alex, Aguirre, Acacia. Improving Health, Safety, and Profits in Extended Hours Operations (Shiftwork). In: Industrial Health, Jg. 43, H. 1, S. 2005; p. 201-208.

29. Kliche T, Schreiner-Kürten K, Wanek V, Koch U. Health Promotion Effectiveness: Testing the German Statutory Health Insurance Agencies Evaluation System in Health Promotion, and Preliminary Findings from 212 Health Training Courses. Gesundheitswesen, 2010, Jun 11(Epub ahead of print).

30. Klotz T, Haisch J, Hurrelmann K. Prävention und Gesundheitsförderung: Ziel ist anhaltend hohe Lebensqualität. Dtsch Arztebl Int. 2006; Band 103:606-9.

31. Knauth P, Hornberger S. Preventive and compensatory measures for shift workers. Occup Med. 2003;Band 53:109.

32. Koller M, Kundi M, Cervinka R. Field studies of shift work at an Austrian oil refinery. I. Health and psychosocial wellbeing of workers who drop out of shift work. Ergonomics. 1978;21:83547.

33. Kordt M. DAK Gesundheitsrepor, IGES Institut Gmbh. Februar 2010

34. Kramer I, Sockoll I, Bödeker W. Die Evidenzbasis für betriebliche Gesundheitsförderung und Prävention-Eine Synopse des wissenschaftlichen Kenntnisstandes. Fehlzeiten-Report. 2008;2008:65-76.

35. Kuhn J. Gute Arbeit: Betriebliche Gesundheitsförderung im gesellschaftlichen Kontext. Arbeitsmed Sozialmed Umweltmed. 2008; Band 43:61-3.

36. Kuhn J, Trojan A. Promoting instead of controlling health-lessons learned, lessons to learn. Gesundheitswesen. 2010;Band 72:23-8.

37. Luxemburger Deklaration zur betrieblichen Gesundheitsförderung in der europäischen Union für betriebliche Gesundheitsförderung 1997; p. 1-8.

38. McCallum M, Sanquist T, Mitler M, Krueger G. Commertial transportation operator fatigue management reference. US Depart- ment of tranportation research and special programs administration (FAA inter alia). 2003; DTRS56-01-T-003.

39. Muecke S. Effects of rotating night shifts: literature review. J Adv Nurs. 2005;50:433-9.

40. Nakao M. Work-related stress and psychosomatic medicine. Biopsychosoc Med. 2010;Band 4:1-8.

41. Niedhammer I, Lert F, Marne MJ. Prevalence of overwight and weight gain in relation to night work in a nurses' cohort. Int J Obes. 1996;20:625-33.

42. Ohayon MM, Guilleminault C. Epidemiology of sleep disorders. In: Lee-Chiong TL, editor. A comprehensive handbook. Hoboken: Wiley; 2006.

43. Opatz JP. Economic impact of worksite health promotion. Champaign: Human kineticks publishers; 1994.

44. Ozminkowski RJ, Wang S, Walsh JK. The direct and indirect costs of untreated insomnia in adults in the United States. Sleep. 2007;30(3):263-73.

45. Pierre Boisard, Damien Cartron, Michel Gollac, Antoine Valeyre, Jean-Baptiste Besançon. Time and work: work intensity, European Foundation for the Improvement of Living and Working Conditions. 2003.

46. Pratt KL, Mattson RH, Weikers NJ, Williams R. EEG activation of epileptics following sleep deprivation: a prospective study of 114 cases. Electroencephalogr Clin Neurophysiol. 1968;24:11-5.

47. Rajaratnam SMW, Arendt J. Health in a 24-h society. Lancet. 2001;Band 358:999-1005.

48. Scott AJ, LaDou J. Health and safety in shift workers. In: Zenz C, Dickerson OB, Horvath EP, editors. Occupational medicine. St Louis: Mosby; 1994. p. 960-86.

49. Spiegel K, Leproult R, Van Cauter E. Impact of sleep debt on metabolic and endocrine function. Lancet. 1999;354:1435-9.

50. Szeisler CA, Allan JS, Stogatz SH, et al. Brights lights reset the human circadian pacemaker independent of the timing of the sleepwake cycle. Science. 1986;233(4764):667-71.

51. Takahashi M, Nakata A, Haratani T, Otsuka Y, Kaida K, Fukasawa K. Psychosocial work characteristics predicting daytime sleepiness in day and shift workers. Chronobiol Int. 2006;23(6):1409-22.

52. Theorell T, Akerstedt T. Day and night work: changes in cholesterol, uric acid, glucose and potassium in serum and in circadian patterns of urinary catecholamine excretion. Acta Med Scand. 1976;200:47-53.

53. Violate JM, Burchfiel CM, Hartley TA, Mnatsakanova A, Fekedulegn D, Andrew ME, et al. Atypical work hours and metabolic syndrome among police officers. Arch Environ Occup Health, Fall. 2009;64(3):194-201.

54. Wolk R, Gami AS, Garcia-Touchard A, Somers VK. Sleep and cardiovascular disease. Curr Probl Cardiol. 2005;30(12):625-62. 